\title{
Research Article \\ Surface State Capture Cross-Section at the Interface between Silicon and Hafnium Oxide
}

\author{
Fu-Chien Chiu \\ Department of Electronic Engineering, Ming Chuan University, Taoyuan, Taiwan 333, Taiwan \\ Correspondence should be addressed to Fu-Chien Chiu; fcchiu@mail.mcu.edu.tw
}

Received 5 August 2013; Accepted 30 September 2013

Academic Editor: Chun-Hsing Shih

Copyright (C) 2013 Fu-Chien Chiu. This is an open access article distributed under the Creative Commons Attribution License, which permits unrestricted use, distribution, and reproduction in any medium, provided the original work is properly cited.

The interfacial properties between silicon and hafnium oxide $\left(\mathrm{HfO}_{2}\right)$ are explored by the gated-diode method and the subthreshold measurement. The density of interface-trapped charges, the current induced by surface defect centers, the surface recombination velocity, and the surface state capture cross-section are obtained in this work. Among the interfacial properties, the surface state capture cross-section is approximately constant even if the postdeposition annealing condition is changed. This effective capture cross-section of surface states is about $2.4 \times 10^{-15} \mathrm{~cm}^{2}$, which may be an inherent nature in the $\mathrm{HfO}_{2} / \mathrm{Si}$ interface.

\section{Introduction}

Hafnium oxide $\left(\mathrm{HfO}_{2}\right)$ has emerged recently as an essential dielectric material in the semiconductor industry, currently being used in logic gate stacks [1] and considered a promising candidate for resistance switching memory devices $[2,3]$ as well as surface passivation of advanced Si solar cells $[4,5]$. Therefore, the determination of surface state capture crosssection at the interface between silicon and hafnium oxide is of great importance for the semiconductor industry, the photovoltaic industry, and the scientific community. The known characteristics of $\mathrm{HfO}_{2}$ thin films include a large band gap $(\sim 6 \mathrm{eV})[6]$, a relatively high dielectric constant $(>20)$ [7], an acceptable breakdown strength $(>4 \mathrm{MV} / \mathrm{cm})$ [7], excellent thermodynamic stability [8], and an effective mass of carrier transportation [9]. In this work, the interface characteristics of the interface-trapped charge density $\left(N_{\text {it }}\right)$, the interface-trapped charge density per area and energy $\left(D_{\mathrm{it}}\right)$, the effective capture cross-section $\left(\sigma_{s}\right)$ of surface states, the surface recombination velocity $\left(s_{o}\right)$, and the minority carrier lifetime $\left(\tau_{\mathrm{FIJ}}\right)$ are identified. The typically electrical measurements of current-voltage $(I-V)$ and capacitance-voltage $(C-V)$ characteristics were performed on the $\mathrm{Al} / \mathrm{HfO}_{2} / \mathrm{p}$-Si metal-oxide-semiconductor (MOS) capacitors and metal-oxide-semiconductor field-effect transistors (MOSFETs). Both gated-diode method $[10,11]$ and subthreshold measurement [12] were applied to evaluate the capture cross-section of interface states for the $\mathrm{HfO}_{2}$ gated MOSFETs. The gated-diode method is a simple way to accurately identify the interfacial characteristics using only a sweeping dc gate voltage, which was introduced in 1966 by Grove and Fitzgerald [10] to determine the surface-state density in MOS structures. According to the gated-diode measurements, the surface recombination velocity and the minority carrier lifetime $\left(\tau_{\mathrm{FIJ}}\right)$ in the field-induced depletion region were extracted. In addition, the interface-trapped charge density per area and energy $\left(D_{\mathrm{it}}\right)$ was determined by using the device subthreshold measurement. Consequently, the effective capture cross-section of surface states was determined to be about $2.4 \times 10^{-15} \mathrm{~cm}^{2}$ by the combination of gated-diode and device subthreshold measurements.

\section{Experiment}

Here, (100) p-type silicon wafers $(1-5 \Omega-\mathrm{cm})$ were used as the starting material. Following the standard cleaning procedures, a $500 \mathrm{~nm} \mathrm{SiO}$, film was grown on silicon wafers by wet oxidation. The source and drain windows were defined by wet etching and doped by phosphorous diffusion. The $\mathrm{HfO}_{2}$ films were deposited by RF magnetron sputtering in argon ambient at room temperature. The flow rate of argon was 13.5 standard cubic centimeters per minute $(\mathrm{sccm})$. The total pressure during deposition was 20 mtorr. The refractive 


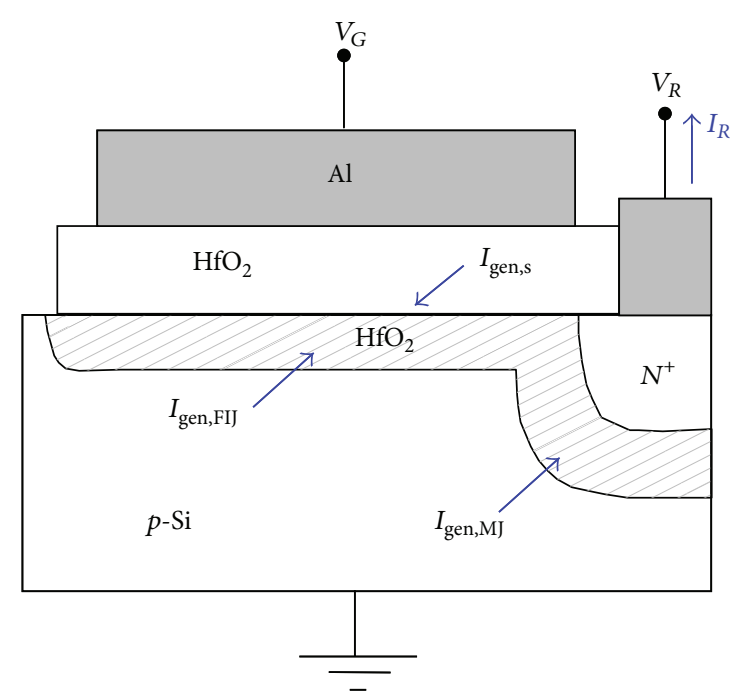

(a)

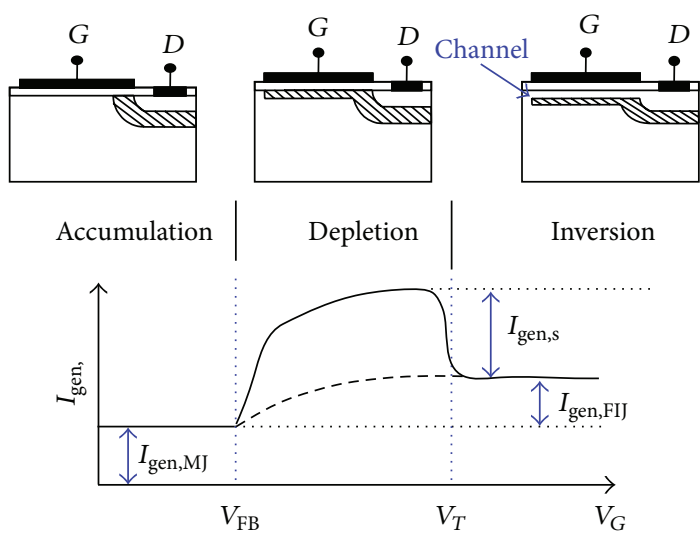

(b)

FIGURE 1: (a) Cross-sectional diagram of an $\mathrm{HfO}_{2}$ gated diode. (b) Effect of the depletion region on the reverse current $I_{R}$ of the gated diode at various gate voltages given a fixed reverse drain voltage $V_{R}$.

index, energy bandgap, and thickness of these thin films were measured by an N\&K analyzer. The optical refractive index $(n)$ and energy bandgap $\left(E_{G}\right)$ were around 1.9-2.1 and 5.6$5.8 \mathrm{eV}$, respectively. The deposited thicknesses of $\mathrm{HfO}_{2}$ thin films ranged from $12 \mathrm{~nm}$ to $47.1 \mathrm{~nm}$. After $\mathrm{HfO}_{2}$ deposition, the postdeposition anneal (PDA) was performed in either $\mathrm{N}_{2}$ or $\mathrm{N}_{2} / \mathrm{O}_{2}$ (i.e., $50 \% \mathrm{~N}_{2}$ and $50 \% \mathrm{O}_{2}$ ) with a flow rate of $3 \mathrm{sccm}$ for $60 \mathrm{~s}$ at $500^{\circ} \mathrm{C}$. According to the X-ray diffraction analysis, the $\mathrm{HfO}_{2}$ films annealed at $500^{\circ} \mathrm{C}$ were amorphous. The aluminum ( $\mathrm{Al}$ ) electrodes were evaporated and patterned using a wet etching process. Postmetallization annealing (PMA) was performed at $400^{\circ} \mathrm{C}$ in $\mathrm{N}_{2}$ for $30 \mathrm{~s}$. The $\mathrm{Al} / \mathrm{HfO}_{2} / p-\mathrm{Si}$ MOS capacitors and MOSFETs were measured by Agilent 4156C semiconductor parameter analyzer and Agilent 4284A impedance analyzer. All the measurements were performed under dark condition. Based on the high-frequency $(1 \mathrm{MHz})$ $C-V$ measurements for the MOS capacitors, the effective dielectric constant of $\mathrm{HfO}_{2}$ films annealed at $500^{\circ} \mathrm{C}$ in $\mathrm{N}_{2}$ or $\mathrm{N}_{2} / \mathrm{O}_{2}$ was evaluated as 18.9 or 19.3 , respectively (not shown here). In this work, the relatively large devices were chosen to avoid the short channel effects which may cause the distortion in analysis of surface state capture cross-section. The channel width $(W)$ is $100 \mu \mathrm{m}$ and the channel length $(L)$ is $19 \mu \mathrm{m}$.

\section{Results and Discussion}

The drastic irregularity of the oxide/Si interface should introduce a large amount of density of states into the forbidden gap near the interface. The interface state may cause the charge trapping and lead to the device instability as well as the degradation of subthreshold swing, off-state current, carrier mobility, and oxide reliability. Charge carriers can be trapped or captured while they come to the physical vicinity of the center of the interface state. The capture cross-section $\left(\sigma_{s}\right)$ of the center is a measure of how close the carrier has to come to the center to be captured. In this work, the gateddiode method is used to identify the interface-trapped charge density $\left(N_{\text {it }}\right)$, the surface recombination velocity $\left(s_{o}\right)$, and the minority carrier lifetime $\left(\tau_{\mathrm{FI}}\right)$ in the field-induced depletion region for the nMOSFET devices using $\mathrm{HfO}_{2}$ gate dielectrics annealed at $500^{\circ} \mathrm{C}$. The test structure described by Grove and Fitzgerald to investigate surface properties in MOS structures is identical to a MOSFET without or with an unconnected source region. In this work, the gated-diode measurement was made using a floating source and a grounded substrate on MOSFET structures, as shown in Figure 1(a). The drain is reversely biased with respect to the substrate $\left(V_{R}=V_{\mathrm{DB}}\right)$. According to the theory of gated-diode method, the reverse current of $P-N$ junctions $\left(I_{R}\right)$ is a function of the gate bias $\left(V_{G}\right)$. The $I_{R}-V_{G}$ characteristics may exhibit three distinct regions [10], as indicated in Figure 1(b). The reverse current of $P-N$ junctions comes from the generation of electron-hole pairs at generation-recombination centers in the depletion region at room temperature. Hence, the magnitude of reverse current depends on the density of such centers and the volume of the depletion region. As the volume of the depletion region in gated diodes depends on the gate voltage, reverse current also depends on the gate voltage. The $\mathrm{HfO}_{2} /$ silicon interface is in the accumulation mode when $V_{G}$ is less than the flat band voltage $V_{\mathrm{FB}}$, and the reverse diode current originates from the generation-recombination centers in the depletion region of the metallurgical junction $\left(I_{\text {gen,MJ }}\right)$. When $V_{\mathrm{FB}}<V_{G}<V_{T}$ (where $V_{T}$ is the threshold voltage), the field-induced junction is depleted, and the rapid increase in the reverse diode current is caused by the generation of electron-hole pairs at the generation-combination centers of the surface region $\left(I_{\text {gen,s }}\right)$ and the field-induced junction depletion region $\left(I_{\text {gen,FIJ }}\right)$. At $V_{G}>V_{T}$, the field-induced junction is in the inversion mode and the reverse diode current is reduced by the filling of the interface-trapped 
charge states by the minority carriers. The magnitude of the reverse diode current is the sum of the generation currents in the depletion volume of the field-induced junction and in that of the metallurgical junction. Based on the Shockley-ReadHall theory for the single-level centers [10], the equations for the gated-diode are written as follows [13-15]:

$$
\begin{gathered}
I_{\mathrm{gen}, \mathrm{MJ}}=q U_{\mathrm{MJ}} W A_{\mathrm{MJ}}, \\
I_{\mathrm{gen}, \mathrm{s}}=\frac{q n_{i} s_{o} A_{g}}{2}, \\
I_{\mathrm{gen}, \mathrm{FIJ}}=q U_{\mathrm{FI} \mathrm{J}} A_{g} x_{d \max }=\frac{q n_{i} A_{g} x_{d \mathrm{max}}}{2 \tau_{\mathrm{FI}}}, \\
s_{o}=\sigma_{s} v_{\mathrm{th}} N_{\mathrm{it}}=\sigma_{s} v_{\mathrm{th}}\left(\pi k T D_{\mathrm{it}}\right), \\
W=\sqrt{\frac{2 \varepsilon_{\mathrm{Si}}\left(N_{A} N_{D}\right)}{q\left(N_{A}+N_{D}\right)}\left(V_{\mathrm{bi}}+V_{R}\right)}, \\
x_{d \max }=\sqrt{\frac{2 \varepsilon_{\mathrm{Si}}}{q N_{A}}\left(2 \phi_{F}+V_{R}\right),}
\end{gathered}
$$

where $n_{i}=9.65 \times 10^{9} \mathrm{~cm}^{-3}$ is the intrinsic carrier concentration in silicon [12]; $A_{\mathrm{MJ}}$ represents the area of the metallurgical junction; $A_{q}=1.9 \times 10^{-5} \mathrm{~cm}^{-2}$ is the gate area; $s_{o}$ is the surface recombination velocity; $\sigma_{s}$ is the effective capture cross-section area; $v_{\text {th }}=10^{7} \mathrm{~cm} / \mathrm{s}$ is the thermal velocity; $V_{\mathrm{bi}}$ is the built-in potential of the $P-N$ junction; $\phi_{F}$ is the quasi-Fermi potential of the majority carriers of the substrate; $W$ is the width of the depletion region of the metallurgical junction; $x_{d \text {, max }}$ is the maximum width of the surface depletion region; $\tau_{0, \mathrm{FI} J}$ is the minority carrier lifetime in the field-induced depletion region; $N_{\mathrm{it}}$ is the interfacetrapped charge density (i.e., density of the single-level surface generation-recombination centers per unit area); $D_{\text {it }}$ is the interface-trapped charge density per area and energy (i.e., the density of uniformly distributed surface generationrecombination centers per unit area and energy); and $U_{\mathrm{MJ}}$, $U_{s}$, and $U_{\mathrm{FIJ}}$ are the generation and recombination rates of carriers per unit volume in the depletion regions of the metallurgical, the surface region, and field-induced region, respectively.

Figure 2 shows the reverse diode current $I_{R}$ versus $V_{G}$ for the $\mathrm{HfO}_{2}$ gated-diodes at $V_{R}=2 \mathrm{~V}$. Through the gated diode method, the surface recombination velocity $\left(s_{o}\right)$ and the minority carrier lifetime $\left(\tau_{\mathrm{FIJ}}\right)$ in the field-induced depletion region can be extracted. For $\mathrm{HfO}_{2}$ films annealed in $\mathrm{N}_{2} / \mathrm{O}_{2}, s_{o}$ and $\tau_{\mathrm{FIJ}}$ are determined to be $4.1 \times 10^{3} \mathrm{~cm} / \mathrm{s}$ and $16 \mathrm{~ns}$. On the other hand, for $\mathrm{HfO}_{2}$ films annealed in $\mathrm{N}_{2}$, $s_{o}$ and $\tau_{\mathrm{FIJ}}$ are determined to be $8.9 \times 10^{3} \mathrm{~cm} / \mathrm{s}$ and $22 \mathrm{~ns}$. Obviously, the reverse diode current of nMOSFETs for $\mathrm{HfO}_{2}$ annealed at $500^{\circ} \mathrm{C}$ in $\mathrm{N}_{2} / \mathrm{O}_{2}$ is smaller than that annealed in $\mathrm{N}_{2}$. The reduction in reverse current may be attributed to the decrease in oxygen vacancy related defects [16-19] in $\mathrm{HfO}_{2}$. The oxygen vacancy is one type of trapping centers and is easily formed in $\mathrm{HfO}_{2}$ due to the transportation of oxygen atoms from $\mathrm{HfO}_{2}$ into $\mathrm{Si}[18,19]$. During the thermal treatment of PDA in $\mathrm{N}_{2} / \mathrm{O}_{2}$ ambient, the oxygen atoms can

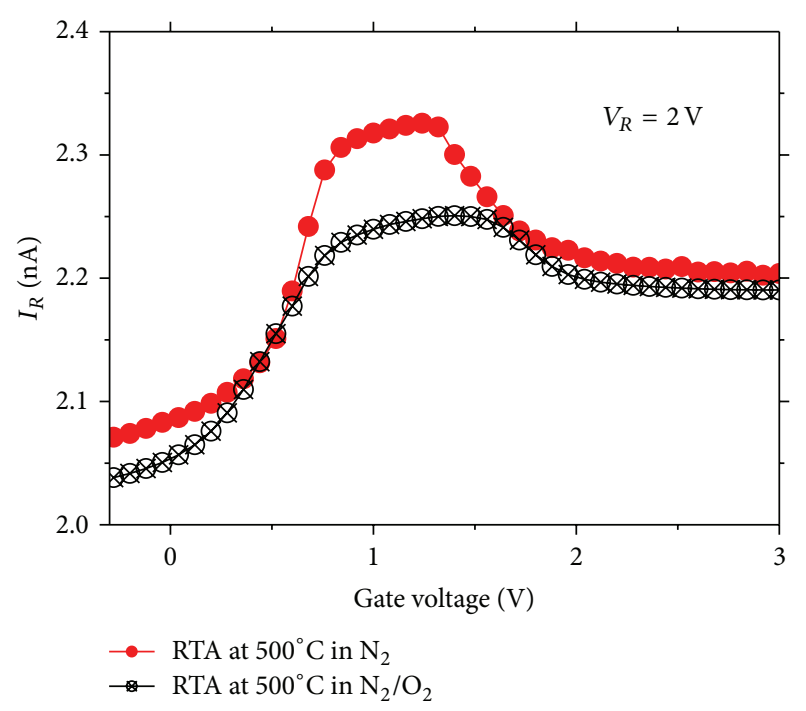

FIgURE 2: Reverse diode current $I_{R}$ of the $\mathrm{HfO}_{2}$ gated diode versus gate voltage $V_{G}$ at $V_{R}=2 \mathrm{~V}$. $V_{R}$ is the reverse bias of the $N^{+}$region of the metallurgical junction.

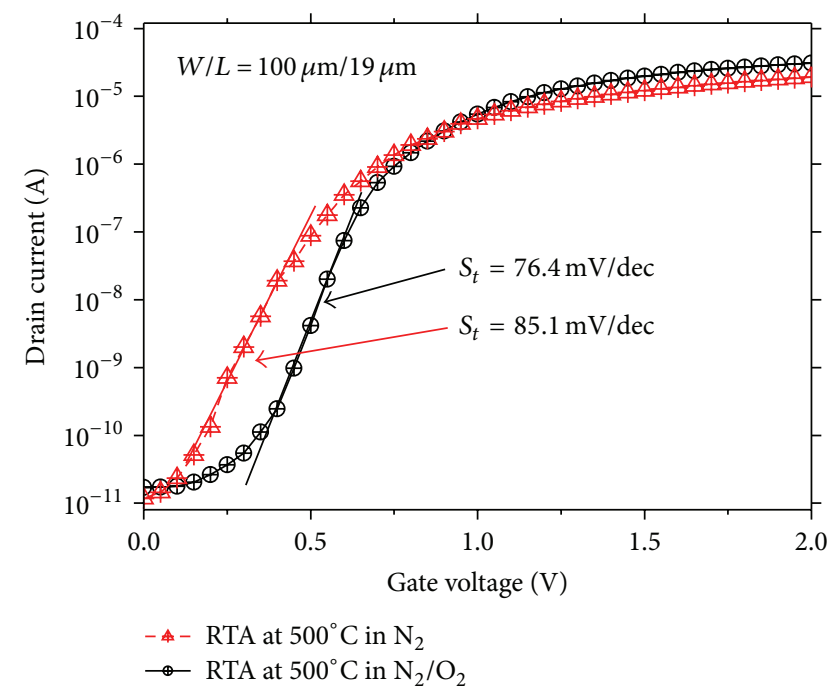

FIGURE 3: $I_{\mathrm{DS}}-V_{\mathrm{GS}}$ characteristics of nMOSFETs fabricated with $\mathrm{HfO}_{2}$ gate dielectrics annealed in $\mathrm{N}_{2}$ and $\mathrm{N}_{2} / \mathrm{O}_{2}$ at $500^{\circ} \mathrm{C}$ for $60 \mathrm{~s}$.

diffuse into the $\mathrm{HfO}_{2}$ films to partially passivate the existing oxygen vacancies. Hence, the reverse diode current can be reduced by $\mathrm{N}_{2} / \mathrm{O}_{2}$ annealing.

Figure 3 shows the $I_{\mathrm{DS}}-V_{\mathrm{GS}}$ characteristics. The $I_{\mathrm{on}} / I_{\text {off }}$ ratio is larger than $10^{6}$ at $V_{D}=0.05 \mathrm{~V}$, indicating that the nMOSFETs with amorphous $\mathrm{HfO}_{2}$ gate dielectrics have a good current switch capability. The subthreshold swings $\left(S_{t}\right)$ for the $\mathrm{HfO}_{2}$ gate dielectrics annealed at $500^{\circ} \mathrm{C}$ in $\mathrm{N}_{2}$ and $\mathrm{N}_{2} / \mathrm{O}_{2}$ are about 85.1 and $76.4 \mathrm{mV} / \mathrm{dec}$, respectively. According to Figure 3, the density of interface traps per area and energy $\left(D_{\text {it }}\right)$ can be determined from the subthreshold swing measurement, because $S_{t}$ is expressed as $2.3(\mathrm{kT} / \mathrm{q})\left[1+\left(\mathrm{C}_{D}+\right.\right.$ $\left.C_{\mathrm{it}}\right) / C_{\text {ox }}$ ] [12], where $C_{D}$ is the depletion-layer capacitance, $C_{i t}$ is the capacitance associated with the interface traps, 
TABLE 1: Capture cross-section of surface states at the oxide/Si interface.

\begin{tabular}{|c|c|c|c|}
\hline Oxide material & Capture cross-section & Deposition method & Measurement technique \\
\hline $\mathrm{SiO}_{2}$ & $1-4 \times 10^{-16} \mathrm{~cm}^{2}$ & Thermal oxidation & Charge pumping [22-24] \\
\hline $\mathrm{ZrO}_{2}$ & $5.8 \times 10^{-16} \mathrm{~cm}^{2}$ & rf sputtering & Gated diode [25] \\
\hline $\mathrm{Al}_{2} \mathrm{O}_{3}$ & $1.7 \times 10^{-15} \mathrm{~cm}^{2}$ & PECVD & DLTS [26] \\
\hline $\mathrm{CeO}_{2}$ & $8.7 \times 10^{-15} \mathrm{~cm}^{2}$ & rf sputtering & Gated diode [27] \\
\hline $\mathrm{CeO}_{2}$ & $9.0 \times 10^{-15} \mathrm{~cm}^{2}$ & rf sputtering & Charge pumping [28] \\
\hline $\mathrm{HfO}_{2}$ & $9.4 \times 10^{-15} \mathrm{~cm}^{2}$ & ALD & Charge pumping [29] \\
\hline $\mathrm{HfO}_{2}$ & $2.4 \times 10^{-15} \mathrm{~cm}^{2}$ & rf sputtering & Gated diode (this work) \\
\hline
\end{tabular}

PECVD: plasma-enhanced chemical vapor deposition, DLTS: deep-level transient spectroscopy, and ALD: atomic layer deposition.

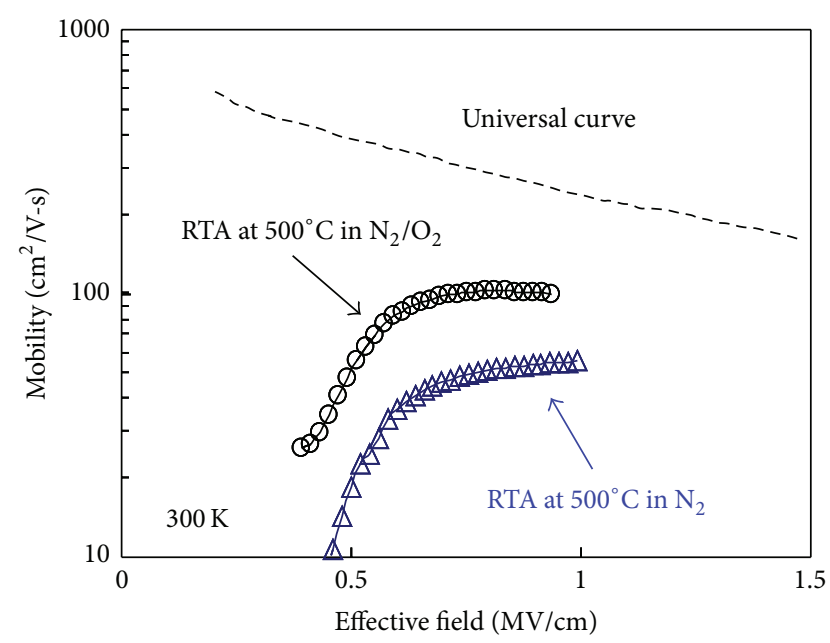

FIGURE 4: Channel electron mobility versus effective surface field for the $\mathrm{HfO}_{2}$ MOSFETs annealed at $500^{\circ} \mathrm{C}$ for $60 \mathrm{~s}$ in $\mathrm{N}_{2}$ and $\mathrm{N}_{2} / \mathrm{O}_{2}$.

and $C_{\mathrm{ox}}$ is the dielectric capacitance. The determined $D_{\mathrm{it}}$ is about $4.6 \times 10^{12}$ and $2.1 \times 10^{12} \mathrm{~cm}^{-2}-\mathrm{eV}^{-1}$ for $\mathrm{HfO}_{2}$ annealed at $500^{\circ} \mathrm{C}$ in $\mathrm{N}_{2}$ and $\mathrm{N}_{2} / \mathrm{O}_{2}$, respectively. Once $D_{\text {it }}$ is determined, $\sigma_{s}$ and $N_{\text {it }}$ can be extracted using (4). For $\mathrm{HfO}_{2}$ annealed in $\mathrm{N}_{2}, \sigma_{s}$ and $N_{\text {it }}$ are extracted to be about $2.4 \times 10^{-15} \mathrm{~cm}^{2}$ and $3.7 \times 10^{11} \mathrm{~cm}^{-2}$, respectively; for $\mathrm{HfO}_{2}$ annealed in $\mathrm{N}_{2} / \mathrm{O}_{2}, \sigma_{s}$ and $N_{\text {it }}$ are extracted to be $2.4 \times$ $10^{-15} \mathrm{~cm}^{2}$ and $1.7 \times 10^{11} \mathrm{~cm}^{-2}$, respectively. It is worthy of note that the same $\sigma_{s}$ value is obtained for $\mathrm{HfO}_{2}$ annealed both in $\mathrm{N}_{2}$ and in $\mathrm{N}_{2} / \mathrm{O}_{2}$. This finding may imply that the capture cross-section of surface states is an inherent nature at the $\mathrm{HfO}_{2} / \mathrm{Si}$ interface. The universal constant of surface state capture cross-section is around $2.4 \times 10^{-15} \mathrm{~cm}^{2}$.

Figure 4 shows the channel electron mobility versus the effective electric field. The effective surface field $\left(E_{\text {eff }}\right)$ and effective channel mobility $\left(\mu_{\text {eff }}\right)$ can be expressed as $E_{\text {eff }}=$ $\left(0.5 Q_{\text {inv }}+Q_{B}\right) / \varepsilon_{\mathrm{Si}}$ and $\mu=\left(I_{\mathrm{DS}} / V_{\mathrm{DS}}\right)(L / W) / Q_{\text {inv }}$, respectively, where $Q_{\text {inv }}$ is the inversion layer charge, $Q_{B}$ is the bulk depletion layer charge, and $\varepsilon_{\mathrm{Si}}$ is the dielectric constant of $\mathrm{Si}$. The linear approximation of $Q_{\text {inv }}, Q_{\text {inv }}=C_{\text {ox }}\left(V_{\mathrm{GS}}-V_{T}\right)$, is used in evaluating the mobility. The rest of the symbols have been defined earlier. The maximum channel electron mobility for the $\mathrm{HfO}_{2}$ annealed in $\mathrm{N}_{2} / \mathrm{O}_{2}$ and $\mathrm{N}_{2}$ was determined to be 102 and $43 \mathrm{~cm}^{2} / \mathrm{V}$ s, respectively. Evidently the $\mathrm{HfO}_{2}$ film annealed in $\mathrm{N}_{2}$ shows lower channel electron mobility than the film annealed in $\mathrm{N}_{2} / \mathrm{O}_{2}$ condition. In addition, the $\mathrm{HfO}_{2}$ device has a lowered mobility as compared to a universal mobility curve in $\mathrm{SiO}_{2}$ MOSFETs [20]. The lowered mobility may come from the larger surface states which cause the increased interface charge scattering [21].

Table 1 lists the capture cross-sections of surface states $\left(\sigma_{s}\right)$ at the interface between silicon and oxides, for example, $\mathrm{SiO}_{2}, \mathrm{ZrO}_{2}, \mathrm{Al}_{2} \mathrm{O}_{3}, \mathrm{CeO}_{2}$, and $\mathrm{HfO}_{2}$ [22-29]. For $\mathrm{SiO}_{2}$, the $\sigma_{s}$ value is $1-4 \times 10^{-16} \mathrm{~cm}^{2}$ [22-24] which is smaller than those of high-k dielectrics. For $\mathrm{CeO}_{2}$, the $\sigma_{s}$ value is around $9 \times 10^{-15} \mathrm{~cm}^{2}$ even if the adopted measurement method is different $[27,28]$. In this work, the experimental results show that the $\mathrm{HfO}_{2}$ films annealed in $\mathrm{N}_{2} / \mathrm{O}_{2}$ have lower interface state density $\left(N_{\text {it }}\right)$ and higher channel electron mobility $\left(\mu_{e}\right)$ compared to the $\mathrm{HfO}_{2}$ films annealed in $\mathrm{N}_{2}$. Although the different PDA conditions lead to the different values of $N_{\text {it }}$ and $\mu_{e}$, the same $\sigma_{s}$ for $\mathrm{HfO}_{2}$ deposited by rf magnetron sputtering is obtained to be around $2.4 \times$ $10^{-15} \mathrm{~cm}^{2}$. This finding may suggest that the capture crosssection of surface states for some thin film deposition method may be an inherent nature at the interface between silicon and hafnium oxide. It is worthy to note that the capture crosssection of surface states may be influenced by the factors of environment temperature, film thickness, film deposition method, and especially surface preparation of Si substrate prior to $\mathrm{HfO}_{2}$ deposition.

\section{Conclusions}

The electrical properties at the $\mathrm{HfO}_{2} / \mathrm{Si}$ interface are investigated by the gated-diode method and the subthreshold measurement. Although the $\mathrm{HfO}_{2}$ films annealed in $\mathrm{N}_{2} / \mathrm{O}_{2}$ result in lower interface state density and higher channel electron mobility compared to the $\mathrm{HfO}_{2}$ films annealed in $\mathrm{N}_{2}$, the determined surface state capture cross-section at the $\mathrm{HfO}_{2} / \mathrm{Si}$ interface is the same. This suggests that the surface state capture cross-section may be an inherent nature at the interface between silicon and hafnium oxide.

\section{Conflict of Interests}

The author declares that there is no conflict of interests regarding the publication of this paper. 


\section{Acknowledgment}

The author would like to thank the National Science Council of Taiwan, for supporting this work under Contract no. NSC 102-2221-E-015-MY2.

\section{References}

[1] G. D. Wilk, R. M. Wallace, and J. M. Anthony, "High-k gate dielectrics: current status and materials properties considerations," Journal of Applied Physics, vol. 89, no. 10, pp. 5243-5275, 2001.

[2] H.-S. P. Wong, H.-Y. Lee, S. Yu et al., "Metal-oxide RRAM," Proceedings of IEEE, vol. 100, no. 6, pp. 1951-1970, 2012.

[3] Y. H. Wu, D. J. Wouters, P. Hendrickx et al., "On the bipolar resistive switching memory using TiN/Hf/ $/ \mathrm{HfO}_{2} / \mathrm{Si} \mathrm{MIS}$ structure," IEEE Electron Device Letters, vol. 34, no. 3, pp. 414-416, 2013.

[4] F. Lin, B. Hoex, Y. H. Koh, J. Lin, and A. G. Aberle, "Lowtemperature surface passivation of moderately doped crystalline silicon by atomic-layer-deposited hafnium oxide films," ECS Journal of Solid State Science and Technology, vol. 2, no. 1, pp. N11-N14, 2013.

[5] J. Wang, S. Sadegh Mottaghian, and M. Farrokh Baroughi, "Passivation properties of atomic-layer-deposited hafnium and aluminum oxides on Si surfaces," IEEE Transactions on Electron Devices, vol. 59, no. 2, pp. 342-348, 2012.

[6] J. Robertson, "Band offsets of wide-band-gap oxides and implications for future electronic devices," Journal of Vacuum Science and Technology B, vol. 18, no. 3, pp. 1785-1791, 2000.

[7] J. McPherson, J.-Y. Kim, A. Shanware, and H. Mogul, “Thermochemical description of dielectric breakdown in high dielectric constant materials," Applied Physics Letters, vol. 82, no. 13, pp. 2121-2123, 2003.

[8] K. J. Hubbard and D. G. Schlom, "Thermodynamic stability of binary oxides in contact with silicon," Journal of Materials Research, vol. 11, no. 11, pp. 2757-2776, 1996.

[9] F.-C. Chiu, "Interface characterization and carrier transportation in metal/ $/ \mathrm{HfO}_{2}$ /silicon structure," Journal of Applied Physics, vol. 100, no. 11, Article ID 114102, 5 pages, 2006.

[10] A. S. Grove and D. J. Fitzgerald, "Surface effects on $P-N$ junctions: characteristics of surface space-charge regions under non-equilibrium conditions," Solid State Electronics, vol. 9, no. 8, pp. 783-806, 1966.

[11] T. Giebel and K. Goser, "Hot carrier degradation of n-channel MOSFET's characterized by a gated-diode measurement technique," IEEE Electron Device Letter, vol. 10, no. 2, pp. 76-78, 1989.

[12] S. M. Sze and K. K. Ng, Physics of Semiconductor Devices, John Wiley \& Sons, Hoboken, NJ, USA, 3rd edition, 2006.

[13] P. L. Castro and B. E. Doal, "Low-temperature reduction of fast surface states associated with thermally oxidized silicon," Journal of the Electrochemical Society, vol. 118, no. 2, pp. 280286, 1971.

[14] P. C. T. Roberts and J. D. E. Beynon, "An experimental determination of the carrier lifetime near the $\mathrm{Si}_{-} \mathrm{SiO}_{2}$ interface," Solid-State Electronics, vol. 16, no. 2, pp. 221-227, 1973.

[15] F.-C. Chiu, W.-C. Shih, J. Y.-M. Lee, and H.-L. Hwang, "An investigation of surface state capture cross-sections for metaloxide-semiconductor field-effect transistors using $\mathrm{HfO}_{2}$ gate dielectrics," Microelectronics Reliability, vol. 47, no. 4-5, pp. 548551, 2007.
[16] K. Shiraishi, K. Yamada, K. Torii et al., "Oxygen-vacancyinduced threshold voltage shifts in Hf-related high-k gate stacks," Thin Solid Films, vol. 508, no. 1-2, pp. 305-310, 2006.

[17] K. Tse, D. Liu, K. Xiong, and J. Robertson, "Oxygen vacancies in high-k oxides," Microelectronic Engineering, vol. 84, no. 9-10, pp. 2028-2031, 2007.

[18] K. Xiong and J. Robertson, "Point defects in $\mathrm{HfO}_{2}$ high $\mathrm{K}$ gate oxide," Microelectronic Engineering, vol. 80, pp. 408-411, 2005.

[19] H. Takeuchi, H. Y. Wong, D. Ha, and T. J. King, "Impact of oxygen vacancies on high-k gate stack engineering," in Proceedings of the 50th IEEE International Electron Devices Meeting (IEDM '04), pp. 829-832, 2004.

[20] S.-I. Takagi, A. Toriumi, M. Iwase, and H. Tango, "On the universality of inversion layer mobility in Si MOSFET's: part Ieffects of substrate impurity concentration," IEEE Transactions on Electron Devices, vol. 41, no. 12, pp. 2357-2362, 1994.

[21] J. R. Hauser, "Extraction of experimental mobility data for MOS devices," IEEE Transactions on Electron Devices, vol. 43, no. 11, pp. 1981-1988, 1996.

[22] D. K. Schroder, Semiconductor Material and Device Characterization, John Wiley \& Sons, Hoboken, NJ, USA, 3rd edition, 2006.

[23] P. Masson, J.-L. Autran, and G. Ghibaudo, "An Improved time domain analysis of the charge pumping current," Journal of NonCrystalline Solids, vol. 280, no. 1-3, pp. 255-260, 2001.

[24] G. Groeseneken, H. E. Maes, N. Beltran, and R. F. de Keersmaecker, "A reliable approach to charge-pumping measurements in MOS transistors," IEEE Transactions on Electron Devices, vol. 31, no. 1, pp. 42-53, 1984.

[25] C.-H. Liu and F.-C. Chiu, "Electrical characterization of $\mathrm{ZrO}_{2} / \mathrm{Si}$ interface properties in MOSFETs with $\mathrm{ZrO}_{2}$ gate dielectrics," IEEE Electron Device Letters, vol. 28, no. 1, pp. 62-64, 2007.

[26] P. Saint-Cast, Y. H. Heo, E. Billot et al., "Variation of the layer thickness to study the electrical property of PECVD $\mathrm{Al}_{2} \mathrm{O}_{3} / \mathrm{c}-\mathrm{Si}$ interface," Energy Procedia, vol. 8, pp. 642-647, 2011.

[27] C.-H. Chen, I. Y.-K. Chang, J. Y.-M. Lee, and F.-C. Chiu, "Electrical characterization of $\mathrm{CeO}_{2} \mathrm{Si}$ interface properties of metal-oxide-semiconductor field-effect transistors with $\mathrm{CeO}_{2}$ gate dielectric," Applied Physics Letters, vol. 92, no. 4, Article ID 043507, 3 pages, 2008.

[28] F.-C. Chiu, S.-Y. Chen, C.-H. Chen, H.-W. Chen, H.-S. Huang, and H.-L. Hwang, "Interfacial and electrical characterization in metal-oxide-semiconductor field-effect transistors with $\mathrm{CeO}_{2}$ gate dielectric," Japanese Journal of Applied Physics, vol. 48, no. 4, Article ID 04C014, 4 pages, 2009.

[29] J.-P. Han, E. M. Vogel, E. P. Gusev et al., "Energy distribution of interface traps in high-k gated MOSFETs," in Proceedings of the Symposium on VLSI Technology, pp. 161-162, June 2003. 

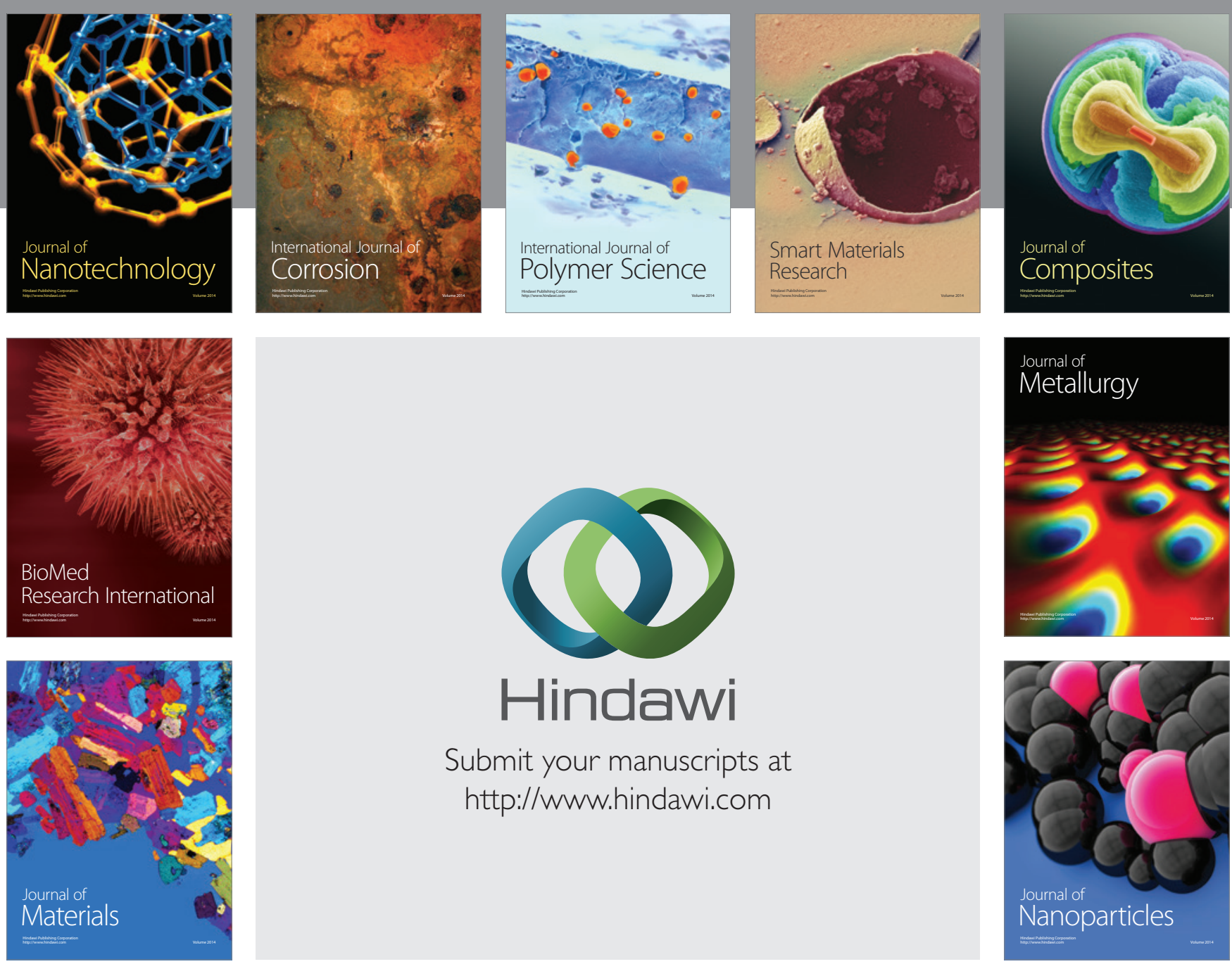

Submit your manuscripts at http://www.hindawi.com
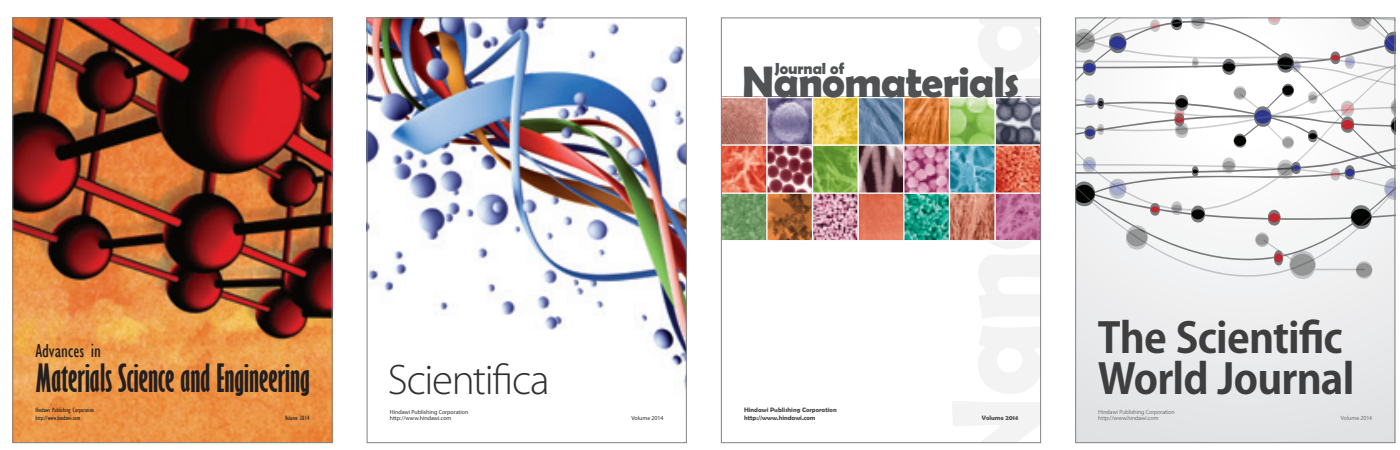

\section{The Scientific World Journal}
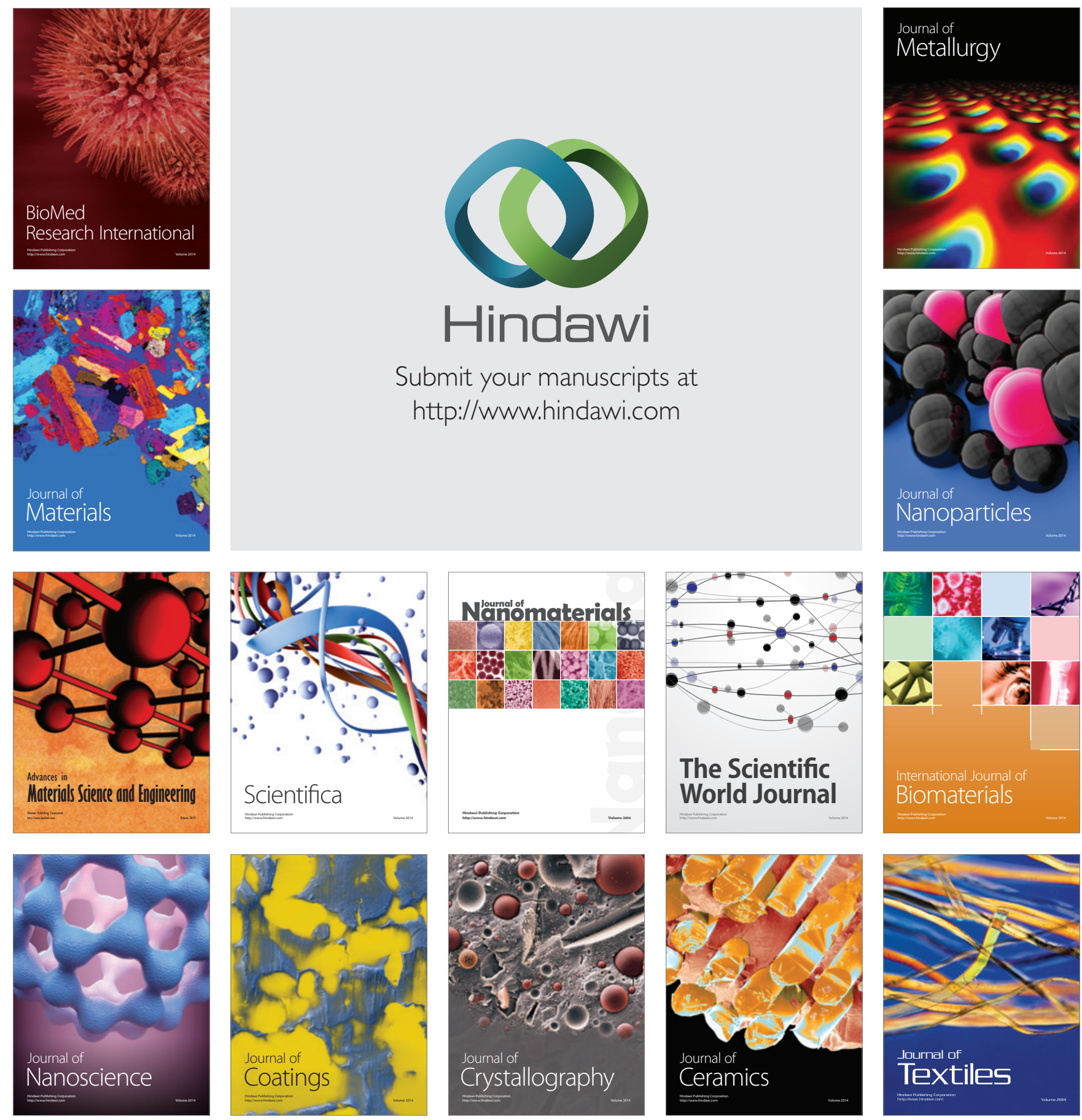